\title{
Role for endovascular therapy in chronic mesenteric ischemia
}

\author{
Romaric Loffroy $M D^{1}$, Eric Steinmetz $M D^{2}$, Boris Guiu $M D^{1}$, Valérie Molin $M D^{2}$, Benjamin Kretz $M D^{2}$, \\ Alice Gagnaire $M D^{3}$, Olivier Bouchot $M D^{2}$, Jean-Pierre Cercueil MD¹, Roger Brenot $M D^{2}$, Denis Krausé $M D^{1}$
}

\begin{abstract}
R Loffroy, E Steinmetz, B Guiu, et al. Role for endovascular therapy in chronic mesenteric ischemia. Can J Gastroenterol 2009;23(5):365-373.

Chronic mesenteric ischemia is a rare condition that is caused by stenosis or occlusion of the mesenteric arteries and usually manifests as abdominal pain. While surgical revascularization has been the standard treatment for symptomatic patients, recent advances in interventional devices and techniques have made endovascular treatment feasible and effective. Percutaneous transluminal angioplasty with stent placement is now recognized as a minimally invasive means of obtaining good long-term results with an acceptable recurrence rate; consequently, the technique is suggested for the primary treatment of chronic mesenteric ischemia. The present article discusses the indications and principles of endovascular treatment, and reviews the literature, with emphasis on short-and long-term outcomes, particularly morbidity and mortality rates.
\end{abstract}

Key Words: Mesenteric ischemia; Percutaneous transluminal angioplasty; Stents; Superior mesenteric artery; Surgical revascularization

$\mathrm{C}$ Thronic mesenteric (or intestinal) ischemia (CMI) is an uncommon condition that accounts for approximately $2 \%$ of revascularization procedures in patients with atheroma. Most patients with CMI are older than 60 years of age, and women are affected three times more often than men. One study (1) found $70 \%$ or higher stenoses of the mesenteric arteries in $17.5 \%$ of patients older than 65 years of age. Ischemia occurs when the blood supply to the intestines is inadequate as a result of lesions affecting one or more of the three mesenteric arteries: the celiac artery (CA), the superior mesenteric artery (SMA) and the inferior mesenteric artery (IMA). Although significant stenosis of at least two of these three arteries is classically considered necessary for symptoms of CMI to occur $(2,3)$, several case series include patients with confirmed CMI due to significant stenosis of a single artery (4-6). Distal lesions carry a greater risk of symptoms than proximal lesions because they prevent the development of collateral arteries. This was demonstrated in three patients with CMI who had isolated lesions of the SMA located distal to the anastomosis with the gastroduodenal artery (7). Conversely, sonographic or autopsy studies (8-10) found severe lesions in multiple mesenteric arteries in patients who had no symptoms of CMI. Untreated symptomatic CMI can lead to potentially fatal malnutrition or acute intestinal ischemia with infarction of the intestine and

\section{Le rôle de la thérapie endovasculaire en présence d'une ischémie mésentérique chronique}

L'ischémie mésentérique chronique est un trouble rare causé par la sténose ou l'occlusion des artères mésentériques, qui se manifeste généralement par des douleurs abdominales. La revascularisation chirurgicale est le traitement classique chez les patients symptomatiques, mais les récents progrès des dispositifs et des techniques interventionnels rendent le traitement endovasculaire faisable et efficace. L'angioplastie transluminale percutanée accompagnée de l'installation d'une endoprothèse est désormais reconnue comme un moyen très peu effractif d'obtenir des résultats à long terme et s'associe à un taux de récurrence acceptable. Par conséquent, la technique est suggérée pour le traitement primaire de l'ischémie mésentérique chronique. Le présent article expose les indications et les principes du traitement endovasculaire et contient une analyse bibliographique s'attardant aux issues à court et à long terme, notamment les taux de mortalité et de morbidité. mesentery - a complication that is associated with a grim prognosis. Therefore, treatment is mandatory for symptomatic patients. The conventional treatment consists of open endarterectomy or bypass surgery, which has a $15 \%$ to $47 \%$ morbidity rate and a $0 \%$ to $17 \%$ mortality rate $(2,11-15)$. Stenoses of mesenteric arteries are usually focal, and are located at the ostium or proximal part of the vessel - two characteristics that make them accessible to endovascular treatment. Endovascular treatment of CMI was first described in 1980 (16) and subsequently produced good results in two small studies $(2,17)$. Encouraged by these results, several groups, including ours, started using endovascular intervention as the first-line treatment for CMI (6). The low incidence of CMI explains the small numbers of patients in published studies and the difficulties encountered in determining the exact role for endovascular treatment.

\section{Etiological setting}

\section{DIAGNOSIS}

Atheroma is by far the most common cause of stenosis of the mesenteric arteries. The proportion of other causes, however, is larger than in other arterial beds. These other causes include Takayasu disease, fibromuscular dysplasia, thromboangiitis obliterans (Buerger's disease), periarteritis nodosum, radiation

${ }^{1}$ Department of Interventional Radiology and Endovascular Therapy; ${ }^{2}$ Department of Cardiovascular Surgery; ${ }^{3}$ Department of Gastroenterology and Hepatology, University of Dijon School of Medicine, Bocage Teaching Hospital, Dijon, France

Correspondence: Dr Romaric Loffroy, Department of Interventional Radiology and Endovascular Therapy, University of Dijon School of Medicine, Bocage Teaching Hospital, 2 bd Maréchal de Lattre de Tassigny, BP 77908, 21079 Dijon Cedex, France.

Telephone 33-38-029-3686, fax 33-38-029-3243, e-mail romaric.loffroy@chu-dijon.fr

Receieved for publication January 17, 2009. Accepted January 18, 2009 


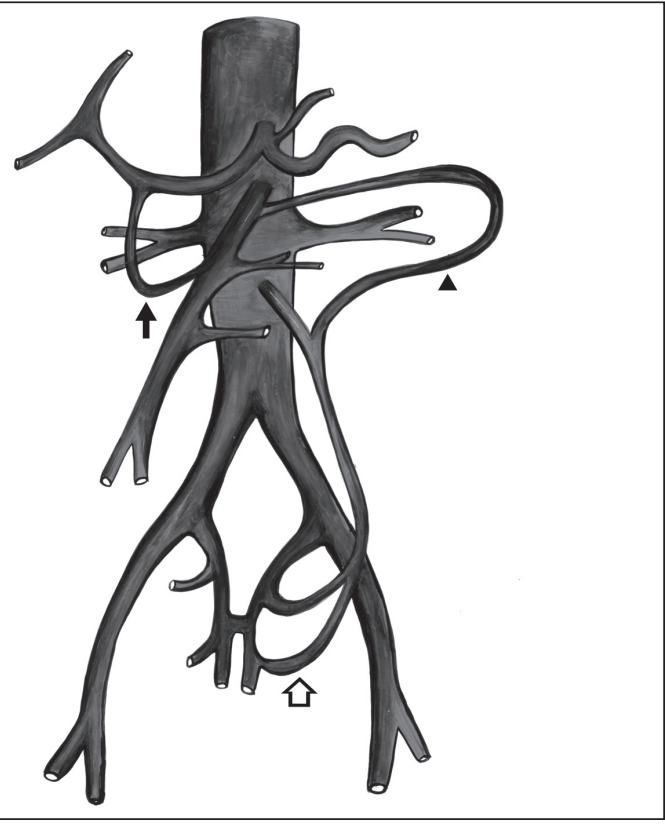

Figure 1) Diagram of the main collateral vessels in patients with occlusion of the celiac artery or superior mesenteric artery (SMA). The pancreaticoduodenal arteries (arrow) connect the celiac artery and proximal SMA. The marginal artery of Drummond and the paracolic arcade (arrowhead) run between the SMA and the inferior mesenteric artery (IMA). When the IMA is also occluded, the systemic vessels (mainly the internal iliac artery) can feed the IMA (reverse flow) and the other vessels via previously described anastomoses (open arrow)

therapy and median arcuate ligament syndrome $(5,18,19)$. Most patients with CMI have multiple cardiovascular risk factors and atheroma lesions in several territories such as the coronary arteries, carotids and/or lower limb arteries. Their life expectancy is, therefore, low.

\section{Mechanisms of CMI}

The occurrence of ischemia is governed mainly by the amount of blood that is circulated to the diseased artery from other arteries (eg, from the CA and IMA to the SMA). There are two main systems of collateral vessels that connect the CA and the IMA to the SMA, respectively (Figure 1). The CA and SMA are connected chiefly by the pancreaticoduodenal arteries, which run between the gastroduodenal artery and the proximal SMA. As with most visceral anastomoses, the blood can flow in either direction depending on the site of the stenosis. The IMA and SMA are connected by the paracolic arcade (Riolan's arch) and marginal artery of Drummond. Patients with narrowing or occlusion of all three mesenteric arteries (CA, SMA and IMA) have prominent phrenic, lumbar and pelvic collateral vessels. Figure 2 shows typical collateral networks in a patient with multiple lesions. Patients with a single lesion may experience pain, whereas others with up to three lesions may be asymptomatic, indicating that the occurrence of painful ischemia does not depend solely on the number of proximal arterial lesions. One other factor involved may be the site of the lesion(s). For instance, an SMA lesion located downstream from the anastomosis with the gastroduodenal artery may present a greater risk of ischemia than a lesion that is located more proximally. Distal stenosis is uncommon because atheroma rarely develops in the distal parts of the mesenteric vessels (9). However, diffuse atherosclerosis of the distal mesenteric vessels develops occasionally, particularly in patients with diabetes or end stage renal disease. These patients may be unable to develop collateral vessels and, consequently, may experience ischemia even with a single, mild stenosis. Another factor in the occurrence of ischemia may be the tempo of lesion progression. In inflammatory diseases such as Takayasu disease, severe occlusion may occur before an efficient collateral network has had time to develop.

Thus, the occurrence of ischemia may be a multifactorial event determined by the pace of lesion progression, the ability of the individual patient to develop collateral vessels and the site of the lesion.

\section{Clinical presentation}

The large number of anastomoses connecting the mesenteric arteries explains the low incidence of symptomatic CMI. When the blood supply to the bowel becomes inadequate, the patient experiences postprandial pain, also known as intestinal angina. Weight loss and a fear of eating develop. Persistent nausea and intermittent diarrhea are less common. Several distinctive clinical pictures that can reveal CMI are described below.

Ischemic gastropathy is associated with a high mortality rate. Incapacitating gastroparesis causes vomiting, postprandial heaviness, gastroduodenal bleeding and delayed gastric emptying during barium opacification $(7,20)$. Women who are heavy smokers are selectively affected. Without treatment at the early stage of gastroparesis, the prognosis is extremely poor $(6,21)$.

Isolated cachexia often prompts costly investigations for a malignancy. As a result, the diagnosis of CMI is often delayed.

Median arcuate ligament syndrome occurs chiefly in young women. During expiration, the CA is pinched by a hypertrophic diaphragmatic crus and by the compact fatty tissue surrounding the sympathetic plexus, which together form a fibrous cord (Figure 3). However, the pathogenesis of this syndrome remains controversial.

\section{Preprocedural imaging}

Investigations that have been suggested for detecting stenosis or occlusion of mesenteric arteries include balloon tonometry (22), fasting and postprandial Doppler ultrasonography (23), magnetic resonance angiography (24) and, most importantly, computed tomographic angiography, which is gaining prominence for patients with good renal function (25). However, Doppler ultrasonography is the simplest investigation and provides both structural and functional information (Figure 4). Arteriography is used less often than in the past, but remains the first step of every endovascular procedure.

\section{Indications for treatment}

Treatment is required for patients with symptomatic CMI. The goals of treatment are to ensure symptom resolution, to correct nutritional status and to prevent intestinal infarction (13). Prophylactic revascularization in patients with asymptomatic CMI who are undergoing aortic procedures for other reasons (eg, aortic aneurysm or aortic occlusive disease) has been suggested (12), as well as prophylactic treatment of asymptomatic lesions before scheduled major abdominal surgery that might compromise the collateral network $(26,27)$. The rationale behind prophylactic revascularization is that nearly one-half of 


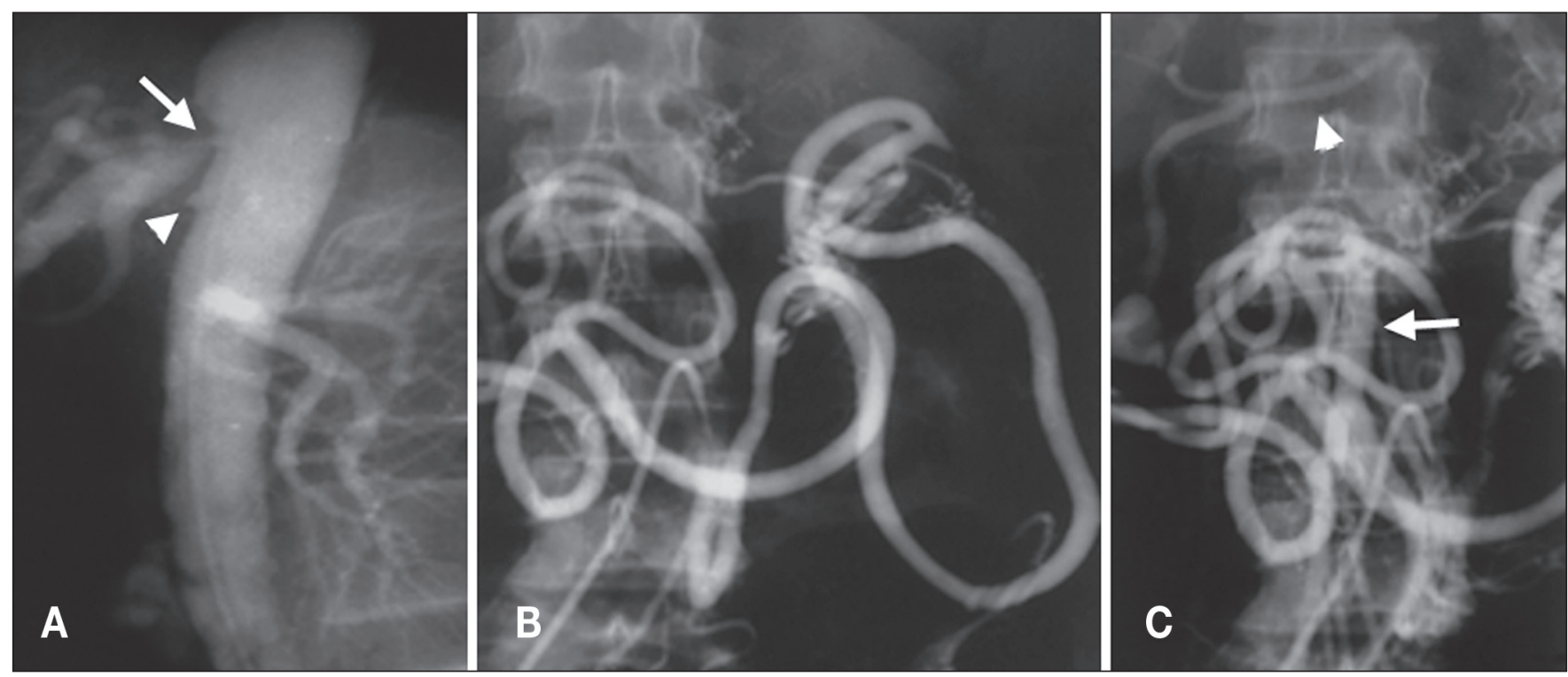

Figure 2) Collateral vessels in a 66-year-old patient with abdominal angina. A Lateral angiogram shows occlusion of the superior mesenteric artery (arrowhead) and severe stenosis of the celiac artery (arrow). B Angiogram obtained with selective injection of contrast medium into the inferior mesenteric artery: unusual serpentine collateral vessels emerging from the marginal artery of Drummond, which is not connected to the paracolic arcade. C Late-phase angiogram showing the superior mesenteric artery (arrow) and celiac artery (arrowhead)

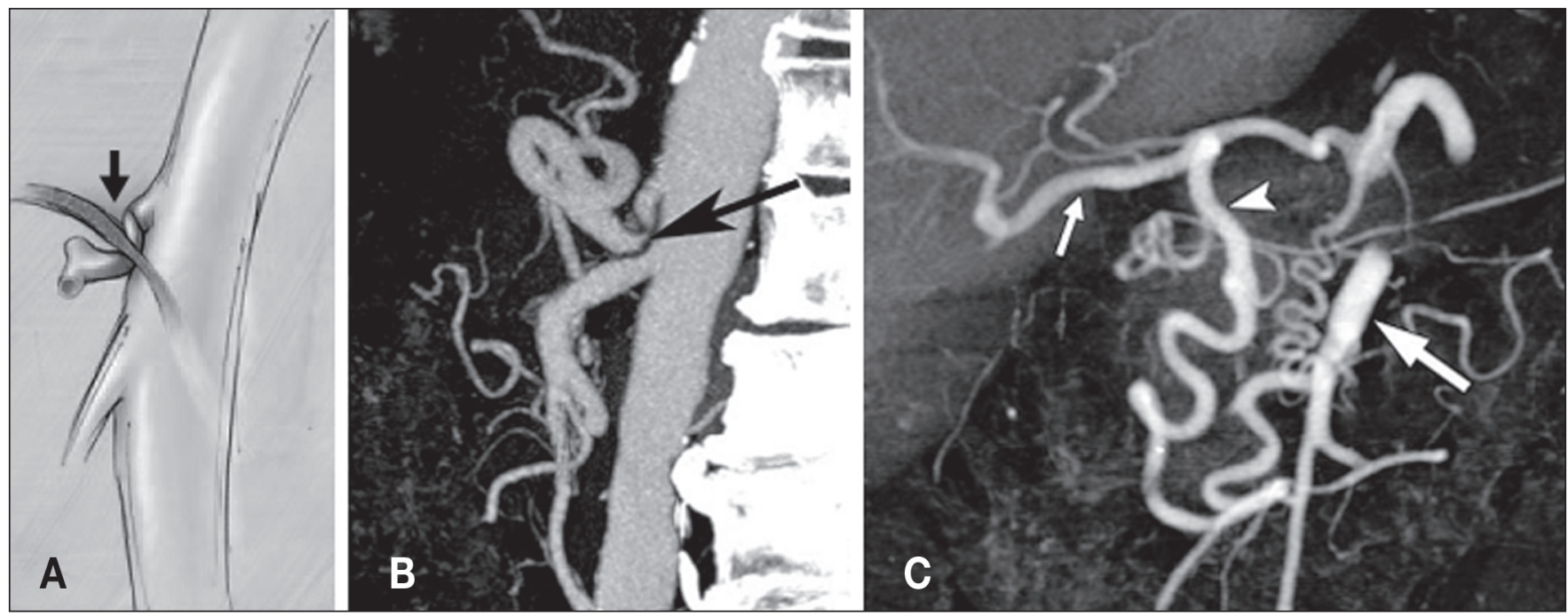

Figure 3) A Diagram showing the mechanism of median arcuate ligament syndrome, in which a hypertrophic diaphragmatic crus puts pressure on the celiac artery (arrow), creating a characteristic pattern of postostial stenosis. B The stenosis is easily seen on a sagittal reformation of a multidetector computed tomography image obtained after injection of an iodinated contrast agent (arrow). C Three-dimensional maximum intensity projection reformation with a coronal section showing opacification of the hepatic artery (small arrow) via retrograde flow from the gastroduodenal artery (arrowhead) originating from the superior mesenteric artery (large arrow)
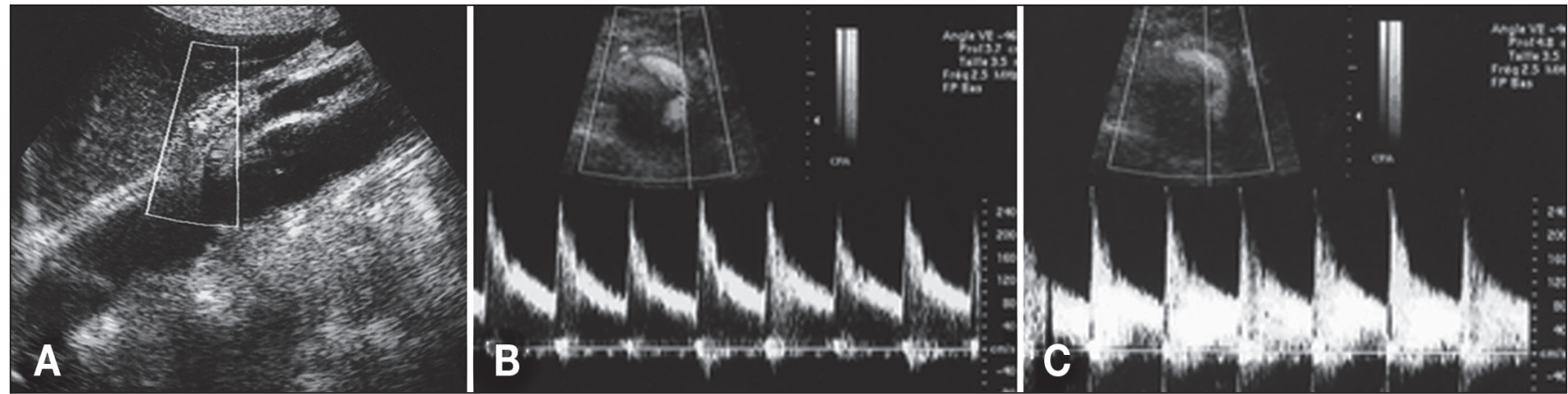

Figure 4) Doppler ultrasonography findings in a patient with isolated stenosis of the celiac artery. A Lateral colour mode image showing colour aliasing. B Lateral Doppler-mode image showing signs of moderate stenosis with increases in systolic and diastolic velocities, as well as mild turbulence. C Lateral Doppler-mode image showing major poststenotic turbulence and Doppler aliasing, which indicate greater than $75 \%$ stenosis 
patients with asymptomatic lesions may experience acute intestinal ischemia as the first manifestation $(28,29)$. However, the natural history of mesenteric artery stenosis remains unclear. In the only study of the clinical course of patients with asymptomatic lesions (29), examination of 980 consecutive aortographies showed significant three-vessel disease in only 15 patients, of whom 13 experienced acute mesenteric ischemia, had vague abdominal symptoms or died during the one- to six-year follow-up.

\section{REVASCULARIZATION TECHNIQUE}

\section{Angiographic findings}

Among investigations for the diagnosis and pretreatment work up, preference is increasingly given to multidetector computed tomography angiography with various reformation modes (multiplanar reconstruction, three-dimensional volume-rendering technique and three-dimensional maximum intensity projection) (Figure 3) (27). Multidetector computed tomography angiography reveals the stenoses; assesses the shape and appearance of the atheroma plaques (calcified, hypodense or heterogeneous); visualizes the distal bed; and provides information on organ function (eg, by showing evidence of bowel wall ischemia). Arteriography is losing ground as a component of the pretreatment strategy, but it remains crucial during treatment. A pigtail catheter placed in the visceral aorta can be used to obtain a lateral view confirming the lesions identified by noninvasive preoperative investigations (Figure 2). Selective catheterization of each of the mesenteric arteries is then performed to measure luminal narrowing and to assess the downstream bed and collateral flow, which are best seen on the anteroposterior view. When one of the arteries is completely occluded, catheterization of one or both of the other arteries is used to determine whether recanalization is feasible. Great caution is required when performing selective catheterization, given the risk of thrombotic events, which may have devastating effects if the artery is the only source of blood to the intestine. The experience of the operator plays a key role in minimizing adverse events.

\section{Choice of route}

At the lower limb, the femoral route is the most widely used and is often chosen for first-line access. We routinely use a long sheath with a diameter of $6 \mathrm{Fr}$, whose tip is advanced to the ostium of the mesenteric arteries. This method provides good stability for catheterizing the mesenteric arteries and allows for the safe introduction of guidewires, balloons and stents. Furthermore, control arteriograms can be obtained at any time during the procedure. For selective catheterization via the femoral route, the most widely used catheter configurations are the cobra, hook, and short- and long-curve sidewinder with a diameter of $4 \mathrm{Fr}$ or $5 \mathrm{Fr}$.

At the upper limb, the axillary route is no longer used because the risk of bleeding is unacceptably high. The humeral route is useful for catheterizing the $\mathrm{CA}$ and provides easier access to mesenteric arteries that have a sharply acute angle of take-off from the aorta. The length of material needed may hinder endovascular navigation in patients with complex, anfractuous or tortuous lesions. However, the longer distance, compared with the femoral route, is offset by the more direct trajectory, with only two curves compared with the three curves encountered when using the femoral route (7). An angulated catheter, such as a vertebral or multipurpose catheter, is generally used for selective views and catheterization.

\section{Choice of material}

We place all of our patients who are scheduled for endovascular treatment on an antiplatelet regimen including acetylsalicylic acid for seven days if not contraindicated. A heparin sodium bolus of $50 \mathrm{IU} / \mathrm{kg}$ to $100 \mathrm{IU} / \mathrm{kg}$ is given intravenously after access is obtained and before endovascular navigation is started. Before selective catheterization, it is important to facilitate access by placing a support in the visceral aorta, which may be either a 5 Fr or 6 Fr guide catheter or a long sheath, with or without a metal jacket. An angled hydrophilic 0.035 -in wire is then advanced across the lesion and used to place a catheter beyond the lesion. The flexible guide is then replaced by a rigid guide that offers sufficient stability for positioning the dilation balloon with or without a stent. When a high-grade stenosis or complete occlusion is present, exchanging the guides may not be feasible or desirable. In this situation, a 0.014 -in wire is recommended to introduce a low-profile balloon for a preliminary dilation step, which is then followed by the usual procedure.

Technological improvements now allow for the performance of the full procedural sequence with 0.014-in-compatible material, making complex lesions easier to cross. Guide catheters with a tip whose angle can be adjusted by the operator were developed recently (27). A filter can be deployed distal to the stenosis using a 0.014 -in wire to protect against distal emboli during advancement of a balloon or stent across the lesion (30). However, the risk of distal embolus is low. Another method for decreasing the embolic risk is the 'no-touch' technique, most notably in patients with severely ulcerated or highly calcified lesions. A long 6 Fr or 7 Fr guide catheter is introduced into the aorta opposite the lesion and kept straight, at a distance of the ostium of the mesenteric artery, using a 0.035-in wire advanced in the thoracic aorta. A 0.014-in wire is advanced in the sheath and pushed across the stenosis in the mesenteric artery and the 0.035 -in wire is then gently removed to decrease trauma to the arterial wall (7).

Vasospasm of the mesenteric arteries may occur during the manoeuvres. Intra-arterial injection of papaverine or buflomedyl is effective for preventing or treating vasospasm (7).

\section{Single-vessel or multiple-vessel revascularization?}

During conventional surgery for CMI, revascularization should be as complete as possible, with recanalization of two or even all three mesenteric arteries, if possible, because repeating the laparotomy would be unduly burdensome. In contrast, endovascular treatment allows for greater freedom in the choice of revascularization strategy. When two arteries are occluded and the third is stenotic, treating the stenotic artery is logical but is associated with a high risk of acute ischemia in the event of a thrombosis or embolus. When one artery is occluded and the other two are stenotic, the most reasonable strategy is angioplasty of the two stenotic arteries, starting with the technically easiest one. It has been suggested that the SMA should be treated first and the CA revascularized only if the first procedure fails (7). Although the chances of a clinical improvement are good when only one of the two arteries is successfully revascularized (either because the procedure failed on one of the arteries or the operator decided to treat a single artery) (6), concomitant treatment of the second artery improves the blood supply to the intestine and prevents symptom recurrence in the event of restenosis of the other treated artery $(27,31)$. The conventional notion that the SMA is the preferred 


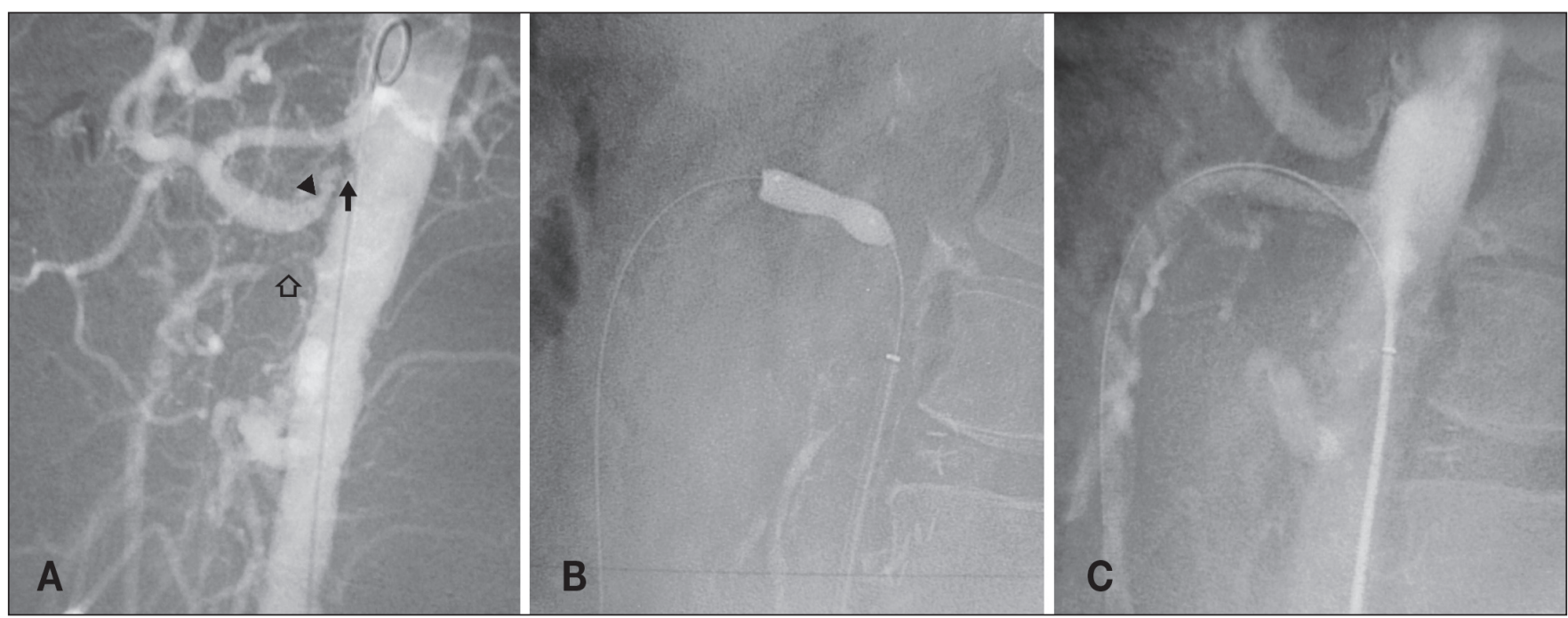

Figure 5) Chronic mesenteric ischemia in a 65-year-old man: arteriography via the femoral artery. A Occlusion of the celiac artery ostium by an atheromatous plaque in the aorta (arrow) and postostial compression of the same artery by an arcuate ligament (arrowhead), with a welldeveloped distal bed and near-occlusion of the superior mesenteric artery (open arrow) with good distal run-off. B Selective catheterization of the superior mesenteric artery using a 0.014-in wire and angioplasty with placement of a balloon-expandable stent. C No stenosis is visible in the superior mesenteric artery on the final images. The celiac artery was left untreated, with a good clinical result
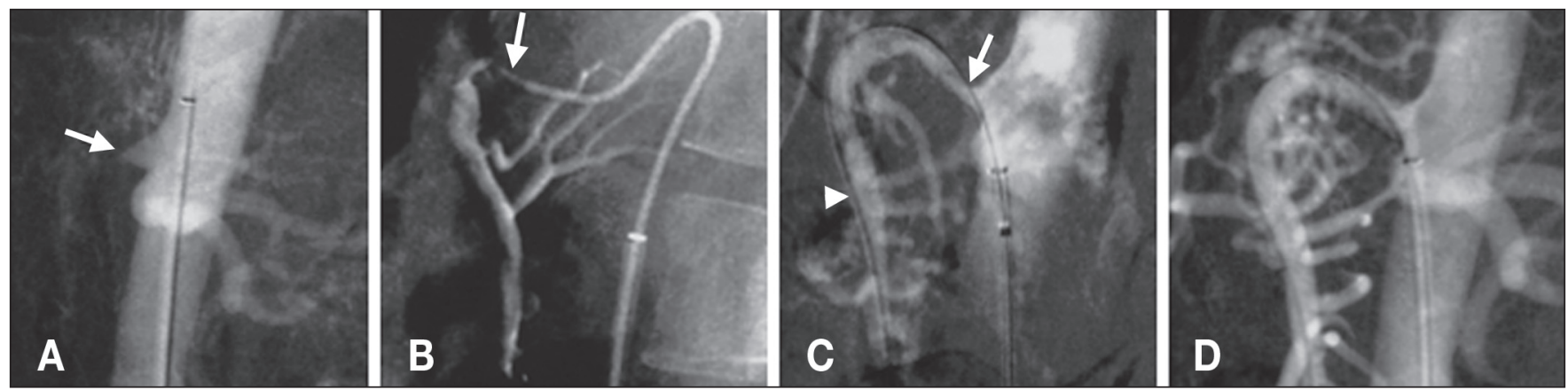

Figure 6) Chronic mesenteric ischemia in a 45-year-old man, with occlusion of both the celiac artery and the superior mesenteric artery. A Lateral angiogram clearly showing a notch in the superior mesenteric artery (arrow). B Angiogram showing the occlusion being crossed by a hydrophilic wire (arrow). C Control angiogram after angioplasty showing good circulation in the superior mesenteric artery (arrowhead) but persistent recoil requiring placement of a stent (arrow). D Final angiogram showing a good result after stent placement

treatment target was challenged by a study (32) in which four patients with IMA stenosis and SMA occlusion treated with IMA angioplasty enjoyed good early and long-term outcomes.

Endovascular recanalization of an occluded mesenteric artery is feasible, particularly when the stump is visible on the arteriogram $(4,7,33)$. One would expect the difficulty of recanalization to increase with the length of the occlusion, although the sample sizes in available studies are too small to determine a cut-off length (34). A greater occlusion length may be associated with a higher risk of emboli, and some teams routinely convert to open surgery when an occlusion is found (12). Additional in situ thrombolysis has been suggested but is associated with a risk of thrombus migration, and has not gained widespread acceptance. This technique may be useful when a recent thrombosis or worsening symptoms occur in a patient who cannot be managed by conventional surgery $(7,35,36)$.

\section{When is stent placement necessary?}

Stenting is classically necessary when the postangioplasty result is unsatisfactory (residual stenosis of $30 \%$ or more, or pressure gradients higher than $15 \mathrm{mmHg}$ ), the lesion is located at the ostium or is markedly eccentric, the patient has a history of dissection after a previous angioplasty procedure or the occlusion is chronic (34). Ostial stenoses of the mesenteric arteries often occur in patients who have tortuous and highly calcified atheroma lesions of the aortic wall, which are often associated with substantial recoil after simple balloon angioplasty. By analogy with the treatment of ostial renal artery stenosis, a stent is usually placed to reinforce the angioplasty $(4,11)$ despite the absence of convincing scientific evidence to support this method (37).

Balloon-expandable stents are preferred, given the high rate of calcifications, because they are highly accurate and generate considerable radial force (Figures 5 and 6). Selfexpandable stents may be useful for more distal or longer lesions of arterial trunks (Figure 7) given their flexibility, and in the event of arterial dissection or occlusion, when clot or atheroma debris need to be trapped by the stent (27). In this situation, postdilation is often needed, particularly when the residual stenosis is $30 \%$ or more, or the pressure gradient is higher than $15 \mathrm{mmHg}$. Stents supported by 0.014 -in platforms are gaining acceptance because their favourable profile facilitates crossing of the lesions. 

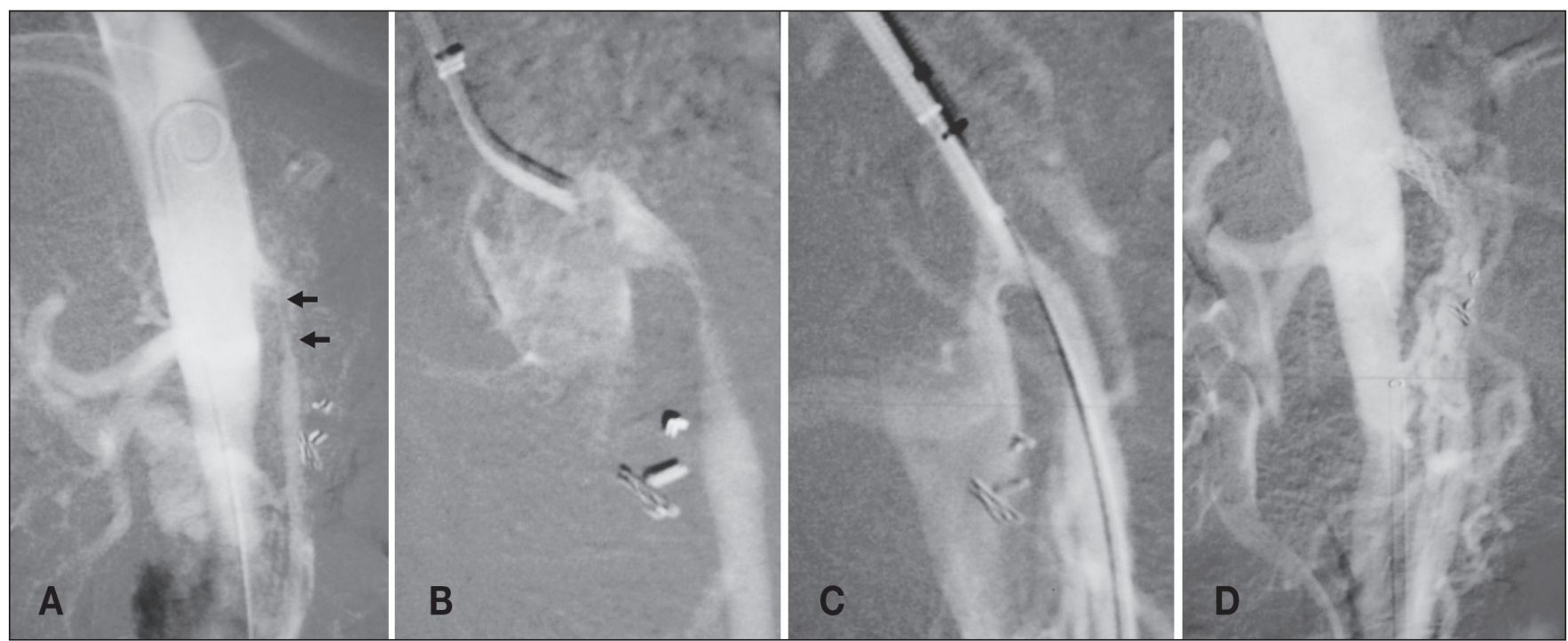

Figure 7) A Aortography via the femoral artery in a 61-year-old woman. Lateral view showing a long stenosis of the trunk of the superior mesenteric artery (arrows). B Catheterization of the ostium via the humeral artery, given the angulation, using a $5 \mathrm{Fr}$ catheter. C Residual stenosis after distal advancement of a 0.035-in wire and simple angioplasty. D Final image after deployment of a self-expandable stent: good result, with resolution of the abdominal pain

\section{COMPLICATIONS}

\section{Puncture site complications}

The most common complications occur at the puncture site. Thrombosis occurs chiefly after humeral artery puncture, particularly when the artery is slender. Long catheters may completely occlude the lumen, thereby promoting the development of a thrombosis. Intravenous injection of heparin immediately after the puncture is a useful preventive measure. Prevention also involves a careful physical examination before the procedure to assess the radial and ulnar circulation, followed by close monitoring after the procedure. Thrombectomy should be performed at the slightest doubt. Bleeding occurs mainly at the femoral, proximal humeral and axillary sites. At the axilla, development of a hematoma within the neurovascular sheath may cause brachial plexus compression. Close monitoring is crucial to ensure early drainage of the hematoma, with the goal of preventing neurological impairment.

\section{Complications involving the treated artery}

Advancing the guide across the stenosis may cause a breach of the intima, thereby inducing dissection of the arterial wall. Stent placement is usually required to prevent anterograde extension of the dissection. The true lumen must be identified downstream from the injury, failing which, open surgery is the only means of saving the artery (7). Unrecognized dissection may lead to inadequate perfusion and intestinal infarction (2). Other arterial complications include thrombosis, which may complicate the treatment of high-grade stenoses, and distal embolus. Both complications are very rare and should be prevented by adequate anticoagulation and atraumatic catheterization.

\section{Other complications}

Other complications consist of systemic complications such as anaphylactic shock or renal failure induced by the contrast agent.

\section{LITERATURE REVIEW OF CLINICAL RESULTS}

Percutaneous treatment of CMI was first reported in 1980 (16). Since then, many published studies $(38-41)$ have confirmed the feasibility of this approach in patients with symptomatic CMI. The technical success rate is high, ranging from $82 \%$ to $100 \%$ in all of the case series that included more than 20 patients over the past decade (Table 1 ). This high rate is probably ascribable to improvements in techniques and equipment. Symptomatic improvement has been reported in up to $95 \%$ of treated patients. The importance of appropriate patient selection is clearly illustrated by data regarding early symptomatic relief after mesenteric revascularization. Five per cent to $19 \%$ of patients experienced no symptomatic relief immediately after the procedure, indicating that the symptoms were likely due to causes other than bowel ischemia. Restenosis rates seem low and are similar to those reported after renal artery angioplasty and stenting. Primary patency rates were $75 \%$ to $85 \%$, with an up to $100 \%$ rate of assisted primary patency. Adverse event rates were similar to those reported with other endovascular procedures, ranging from $0 \%$ to $29 \%$ in the larger series, with puncture site complications accounting for most of the events. Newer, low-profile manoeuvreable stent platforms will probably further reduce this complication rate.

A meta-analysis (34) of 16 studies (published between 1995 and 2006) comprising 328 patients with CMI who were treated using endovascular techniques was published recently. Anecdotal case reports (most of which reported successful treatment) and studies that included fewer than five patients were excluded. A subgroup analysis was conducted to compare three endovascular strategies: angioplasty alone $(n=66)$, angioplasty with selective stenting $(\mathrm{n}=128)$ and primary stenting $(n=134)$. The reason for stent placement in the selectivestenting group was unclear (eg, technical failure of the angioplasty, decision of the operator, availability of the material, characteristics of the lesion). Variables that were compared in the three subgroups included technical success, freedom from 
TABLE 1

Outcomes in case series that included more than 20 patients treated with endovascular intervention for chronic mesenteric ischemia over a 10-year period

\begin{tabular}{|c|c|c|c|c|c|c|c|}
\hline Reference, year & $\begin{array}{c}\text { Patients, n/mean } \\
\text { age, years }\end{array}$ & $\begin{array}{c}\text { Technical } \\
\text { success, \% }\end{array}$ & $\begin{array}{l}\text { Clinical success } \\
\left.\text { (Early*/late }^{\dagger}\right), \%\end{array}$ & $\begin{array}{c}\text { Complication } \\
\text { rate, } \%\end{array}$ & $\begin{array}{c}\text { 30-day } \\
\text { mortality, \% }\end{array}$ & $\begin{array}{l}\text { Symptomatic } \\
\text { restenosis, \% }\end{array}$ & $\begin{array}{c}\text { Mean } \\
\text { follow-up, } \\
\text { months }\end{array}$ \\
\hline Lee et al (41), 2008 & $31 / 70$ & 97 & $\mathrm{NA} / 72$ & 6 & 14 & 44 & 34 \\
\hline Sarac et al (40), 2008 & $65 / 70$ & 94 & 85/NA & 20 & 8 & NA & 12 \\
\hline Atkins et al (39), 2007 & $31 / \mathrm{NA}$ & 97 & $87 / 61$ & 29 & 3 & 23 & 15 \\
\hline Silva et al (37), 2006 & $59 / 67$ & 97 & $85 / 71$ & 3 & 0 & 34 & 38 \\
\hline Landis et al (34), 2005 & $29 / 62$ & 97 & $90 / 66$ & 14 & 7 & 34 & 28 \\
\hline Van Wanroij et al (38), 2004 & 27/NA & 93 & $81 / 67$ & 11 & 0 & 22 & 19 \\
\hline AbuRahma et al (11), 2003 & $22 / 69$ & 95 & $95 / 50$ & 0 & 0 & 32 & 26 \\
\hline Matsumoto et al (33), 2002 & $33 / 63$ & 82 & $88 / 73$ & 15 & 0 & 15 & 38 \\
\hline Kasirajan et al (12), 2001 & $28 / 72$ & 100 & NA/61 & 18 & 11 & 18 & 24 \\
\hline Maspes et al (5), 1998 & 23/NA & 87 & $87 / 78$ & 9 & 0 & 17 & 27 \\
\hline All studies & $348 / 68$ & 94 & $87 / 67$ & 12 & 4 & 27 & 26 \\
\hline
\end{tabular}

*Less than 0 days, ${ }^{\dagger}$ More than 30 days. NA Not available

TABLE 2

Comparison of simple angioplasty, simple angioplasty with selective stenting and primary stenting in patients with chronic mesenteric ischemia

\begin{tabular}{|c|c|c|c|c|}
\hline & Simple angioplasty $(n=66)$ & $\begin{array}{l}\text { Angioplasty with selective } \\
\text { stenting }(n=128)\end{array}$ & $\begin{array}{l}\text { Primary stenting } \\
\qquad(n=134)\end{array}$ & $\begin{array}{c}\text { Total } \\
(n=328)\end{array}$ \\
\hline Patients, n & 57 & 113 & 122 & 292 \\
\hline Immediate technical success rate & $83^{\star \star * \star *}$ & $92 * *$ & $95^{\star \star \star}$ & 91 \\
\hline 30-day clinical success rate (no symptoms) & 89 & 90 & 91 & 90 \\
\hline Long-term clinical success rate without reoperation & 81 & 76 & 72 & 75 \\
\hline 30-day complication rate & $11^{*}$ & $15^{\star \star \star \star}$ & $3 * \star \star \star \star *$ & 9 \\
\hline 30-day mortality rate & 5 & 3 & 4 & 2 \\
\hline Restenosis rate & 21 & 26 & 35 & 28 \\
\hline
\end{tabular}

Data presented as \%, unless specified otherwise. Data from 16 studies published between 1995 and 2006 that included more than five patients. Data comprised of 328 patients with a mean follow-up of 26 months. ${ }^{\star} P=0.02 ;{ }^{*} P=0.06 ;{ }^{* \star} P=0.007 ;{ }^{\star \star \star *} P=0.0006$. Adapted from reference 34

early and late symptom recurrence, complication rate, mortality rate and restenosis rate (Table 2 ). Interestingly, technical success was significantly more common with stenting than with angioplasty alone, but restenosis rates were not significantly different between the two techniques. The complication rate was significantly higher with angioplasty alone than with the other two strategies, probably in part because of the learning curve, and in part, to the material which was less sophisticated because most of the angioplasty-only procedures were performed before 1998. The restenosis rate was significantly higher in the primary stenting subgroup. This meta-analysis (34) shows that endovascular treatment is safe and is associated with very low morbidity and mortality rates. Stenting increases the immediate success rate and also increases the long-term risk of restenosis, which is fairly well tolerated. Although the long-term patency rate is lower than reported with conventional surgery, the low morbidity rate gives endovascular treatment a place of choice in the management of CMI, particularly in high-risk patients (34).

\section{TOPICS OF INTEREST}

Acute mesenteric ischemia

Acute mesenteric ischemia requires emergent conventional surgery to revascularize the artery and, above all, to visually assess the viability of the ischemic bowel segment. Endovascular treatment may be considered in a few situations, namely, symptoms of acute mesenteric ischemia without evidence of peritoneal irritation (indicating extremely early stage ischemia), a very high operative risk, infection of the peritoneal cavity with no available autologous vessel for grafting or compassionate treatment. Otherwise, there is no role for endovascular treatment. In situ thrombolysis and percutaneous angioplasty have been used in a few patients with some measure of success $(42-44)$.

\section{Median arcuate ligament syndrome}

The treatment for median arcuate ligament syndrome should be directed against the cause of the compression. Stents, however strong, fail to reliably protect against the constricting band, which moves with the breathing cycle. Fracture of the stent is unavoidable and may lead to CA thrombosis or distal embolus. Except for compassionate treatment, percutaneous angioplasty (even with stenting) is not appropriate in patients with median arcuate ligament syndrome. Stenting has been suggested as a diagnostic test, with a positive result confirming the need for surgery via laparotomy or laparoscopy (34).

Endovascular versus open surgical treatment

Conventional surgical treatment is the reference standard. The immediate success rate is nearly 100\%; long-term success rates are high. The best outcomes in published studies were a 14-day 
hospital stay (45), a $93 \%$ long-term patency rate (46), a $79 \%$ nine-year assisted primary patency rate (47) and a greater than $60 \%$ five-year survival rate (15). Although these long-term outcomes are better than outcomes with endovascular surgery, the invasiveness of conventional surgery is a disadvantage in patients with CMI, most of whom have a high operative risk. With conventional surgery, postoperative mortality ranges from $0 \%$ to $17 \%$ and postoperative morbidity from $15 \%$ to $47 \%$ (2,11-15). Endovascular intervention is safer in the short term, with $0 \%$ to $11 \%$ mortality and $0 \%$ to $18 \%$ morbidity (34). No prospective controlled trials comparing conventional surgery and endovascular treatment are available. Three major centres in the United States retrospectively reviewed their experience with both methods.

At the Cleveland Clinic Foundation (USA), 28 patients treated with angioplasty and stenting were compared with 85 patients who were treated during an earlier period with open revascularization (12). No significant differences were found for mortality, morbidity or restenosis rates. Long-term symptom recurrence was noted in 11 of 28 (39\%) and 10 of 85 (12\%) patients, respectively, which led the authors to recommend first-line open surgery in patients who have an acceptable surgical risk.

At the Mayo Clinic (USA), 229 patients were treated with open surgery or endovascular intervention over a 14-year period (48). The morbidity rate was higher and the hospital stay longer with open surgery, but mortality was not significantly different (2.5\% for open surgery versus $3.6 \%$ with endovascular treatment). After endovascular treatment, restenosis was five times more common and symptom recurrence seven times more common than after open surgery. The number of

\section{REFERENCES}

1. Hansen KJ, Wilson DB, Craven TE, et al. Mesenteric artery disease in the elderly. J Vasc Surg 2004:40:45-52.

2. Allen RC, Martin GH, Rees CR, et al. Mesenteric angioplasty in the treatment of chronic intestinal ischemia. J Vasc Surg 1996;24:415-23.

3. Mikkelsen WP. Intestinal angina: Its surgical significance. Am J Surg 1957;94:262-9.

4. Sharafuddin MJ, Olson CH, Sun S, et al. Endovascular treatment of celiac and mesenteric arteries stenoses: Applications and results. J Vasc Surg 2003;38:692-8.

5. Maspes F, Mazzetti di Pietralata G, Gandini R, et al. Percutaneous transluminal angioplasty in the treatment of chronic mesenteric ischemia: Results and 3 years of follow-up in 23 patients. Abdom Imaging 1998;23:358-63.

6. Steinmetz E, Tatou E, Favier-Blavoux C, et al. Endovascular treatment as first choice in chronic intestinal ischemia. Ann Vasc Surg 2002;16:693-9.

7. Cognet F, Ben Salem D, Dranssart M, et al. Chronic mesenteric ischemia: Imaging and percutaneous treatment. Radiographics 2002;22:863-80.

8. Croft RJ, Menon GP, Marston A. Does 'intestinal angina' exist? A critical study of obstructed visceral arteries. Br J Surg 1981;68:316-8.

9. Jarvinen O, Laurikka J, Sisto T, et al. Atherosclerosis of the visceral arteries. Vasa 1995;24:9-14.

10. Roobottom CA, Dubbins PA. Significant disease of the celiac and superior mesenteric arteries in asymptomatic patients: Predictive value of Doppler sonography. AJR Am J Roentgenol 1993;161:985-8.

11. AbuRahma AF, Stone PA, Bates MC, Welch CA. Angioplasty/ stenting of the superior mesenteric artery and celiac trunk: Early and late outcomes. J Endovasc Ther 2003;10:1046-53.

12. Kasirajan K, O'Hara PJ, Gray BH, et al. Chronic mesenteric ischemia: Open surgery versus percutaneous angioplasty and stenting. J Vasc Surg 2001;33:63-71.

13. Rose SC, Quigley TM, Raker EJ. Revascularisation for chronic mesenteric ischemia: Comparison of operative arterial bypass grafting and percutaneous transluminal angioplasty. J Vasc Interv Radiol 1995;6:339-49. reoperations during follow-up was four times lower after open surgery. The authors recommended open surgery, particularly for patients in good clinical condition.

At the Massachusetts General Hospital (USA), of 80 patients treated over a 14 -year period, 31 were managed by endovascular methods (mean follow-up 15 months) and 49 by open surgery (mean follow-up 42 months) (39). Heart failure and renal failure were more prevalent in the endovascular treatment group. Although patency rates were better after open surgery, no differences were found for mortality, morbidity or symptom recurrence. The authors concluded that patients should be selected for endovascular or open treatment based on anatomical criteria, clinical risk factors and patient preference.

\section{CONCLUSION}

Only a vast, prospective, randomized controlled trial comparing endovascular treatment with open surgical treatment can determine whether one of these methods is superior to the other. However, the low incidence of symptomatic CMI makes such a trial extremely unlikely. Endovascular treatment has been advocated for high-risk patients and for patients with vague symptoms and a doubtful diagnosis. In everyday practice, endovascular treatment is being used increasingly as the firstline treatment of choice, with open surgery being reserved for patients who fail this treatment modality. We have adopted this strategy at the Bocage Teaching Hospital, Dijon, France. Our results are satisfactory, given the usually fragile general health of these patients. Restenosis, although common, is well tolerated or asymptomatic. Furthermore, open surgery can be performed when repeated endovascular interventions fail.

14. Cunningham CG, Reilly LM, Rapp JH, et al. Chronic visceral ischemia: Three decades of progress. Ann Surg 1991;214:276-88.

15. Mateo RB, O'Hara PJ, Hertzer NR, et al. Elective surgical treatment of symptomatic chronic mesenteric occlusive disease: Early results and late outcomes. J Vasc Surg 1999;29:821-32.

16. Furrer J, Gruntzig A, Kugelmeier J, Goebel N. Treatment of abdominal angina with percutaneous dilatation of an arteria mesenterica stenosis. Preliminary communication. Cardiovasc Intervent Radiol 1980;3:43-4.

17. Matsumoto AH, Tegtmeyer CJ, Fitzcharles EK, et al. Percutaneous transluminal angioplasty of visceral arterial stenoses: Results and long-term clinical follow-up. J Vasc Interv Radiol 1995;6:165-74.

18. Zelenock GB, Graham LM, Whitehouse WM Jr, et al. Splanchnic arteriosclerotic disease and intestinal angina. Arch Surg 1980;115:497-501.

19. Medlicott SAC, Beaudry P, Morris G, et al. Intestinal thromboangiitis obliterans in a woman: A case report and discussion of chronic ischemic changes. Can J Gastroenterol 2003;17:559-61.

20. Liberski SM, Koch KL, Atnip RG, Stern RM. Ischemic gastroparesis: Resolution after revascularisation. Gastroenterology 1990;99:252-7.

21. Casey KM, Quigley TM, Kozarek RA, Raker EJ. Lethal nature of ischemic gastropathy. Am J Surg 1993;165:646-9.

22. Boley SJ, Brandt LJ, Veith FJ, et al. A new provocative test for chronic mesenteric ischemia. Am J Gastroenterol 1991;86:888-91.

23. Gentile AT, Moneta GL, Lee RW, et al. Usefulness of fasting and postprandial duplex ultrasound examinations for predicting highgrade superior mesenteric artery stenosis. Am J Surg 1995;169:476-9.

24. Meaney JF, Prince MR, Nostrant TT, Stanley JC. Gadoliniumenhanced MR angiography of visceral arteries in patients with suspected chronic mesenteric ischemia. J Magn Reson Imaging 1997;7:171-6.

25. Fleischmann D. MDCT of renal and mesenteric vessels. Eur Radiol 2003;13:94-101.

26. Connolly JE, Stemmer EA. Intestinal gangrene as the result of mesenteric arterial steal. Am J Surg 1973;126:197-204.

27. Razavi M, Chung HH. Endovascular management of chronic mesenteric ischemia. Tech Vasc Interv Radiol 2004;7:155-9. 
28. Stoney RJ, Cunningham CG. Acute mesenteric ischemia. Surgery 1993;114:489-90.

29. Thomas JH, Blake K, Pierce GE, et al. The clinical course of asymptomatic mesenteric arterial stenosis. J Vasc Surg 1998;27:840-4.

30. Brown DJ, Schermerhorn ML, Powell RJ, et al. Mesenteric stenting for chronic mesenteric ischemia. J Vasc Surg 2005;42:268-74.

31. McAfee MK, Cherry KJ Jr, Naessens JM, et al. Influence of complete revascularisation on chronic mesenteric ischemia. Am J Surg 1992;164:220-4.

32. Matsumoto AH, Angle JF, Spinosa DJ, et al. Percutaneous transluminal angioplasty and stenting in the treatment of chronic mesenteric ischemia: Results and long-term follow-up. J Am Coll Surg 2002;194:22-31.

33. Landis MS, Rajan DK, Simons ME, et al. Percutaneous management of chronic mesenteric ischemia: Outcomes after intervention. J Vasc Interv Radiol 2005;16:1319-25.

34. Kougias P, El Sayed HF, Zhou W, Lin PH. Management of chronic mesenteric ischemia: The role of endovascular therapy. J Endovasc Ther 2007;14:395-405.

35. Maleux G, Wilms G, Stockx L, et al. Percutaneous recanalization and stent placement in chronic proximal superior mesenteric artery occlusion. Eur Radiol 1997;7:1228-30.

36. Tytle TL, Prati RC Jr. Percutaneous recanalization in chronic occlusion of the superior mesenteric artery. J Vasc Interv Radiol 1995;6:133-6.

37. Silva JA, White CJ, Collins TJ, et al. Endovascular therapy for chronic mesenteric ischemia. J Am Coll Cardiol 2006;47:944-50.

38. Van Wanroij JL, Van Peterson AS, Huisman AB, et al. Endovascular treatment of chronic splanchnic syndrome. Eur J Vasc Endovasc Surg 2004;28:193-200.
39. Atkins MD, Kwolek CJ, LaMuraglia GM, et al. Surgical revascularisation versus endovascular therapy for chronic mesenteric ischemia: A comparative experience. J Vasc Surg 2007;45:1162-71.

40. Sarac TP, Altinel O, Kashyap V, et al. Endovascular treatment of stenotic and occluded visceral arteries for chronic mesenteric ischemia. J Vasc Surg 2008;47:485-91.

41. Lee RW, Bakken AM, Palchik E, Saad WE, Davies MG. Long-term outcomes of endoluminal therapy for chronic atherosclerotic occlusive mesenteric disease. Ann Vasc Surg 2008;22:541-6.

42. Gallego AM, Ramirez P, Rodriguez JM, et al. Role of urokinase in the superior mesenteric artery embolism. Surgery 1996;120:111-3.

43. Ramirez-Ponce MP, Mateos JC, Carrion N, Bellido JA. Voltage-dependent potassium channels in white adipocytes. Biochem Biophys Res Commun 1996;223:250-6.

44. VanDeinse WH, Zawacki JK, Phillips D. Treatment of acute mesenteric ischemia by percutaneous transluminal angioplasty. Gastroenterology 1986;91:475-8.

45. Derrow AE, Seeger JM, Dame DA, et al. The outcome in the United States after thoracoabdominal aortic aneurysm repair, renal artery bypass, and mesenteric revascularisation. J Vasc Surg 2001;34:54-61.

46. Nyman U, Ivancev K, Lindh M, Uher P. Endovascular treatment of chronic mesenteric ischemia: Report of five cases. Cardiovasc Intervent Radiol 1998;21:305-13.

47. Foley MI, Moneta GL, Abou-Zamzam AM Jr, et al. Revascularisation of the superior mesenteric artery alone for treatment of intestinal ischemia. J Vasc Surg 2000;32:37-47.

48. Oderich GS, Bower TC, Misra S, et al. Open versus endovascular revascularisation for chronic mesenteris ischemia: Risk stratified outcome. Society for Vascular Surgery Annual Meeting. Philadelphia, June 1 to 4, 2006. 


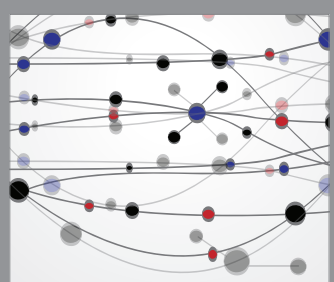

The Scientific World Journal
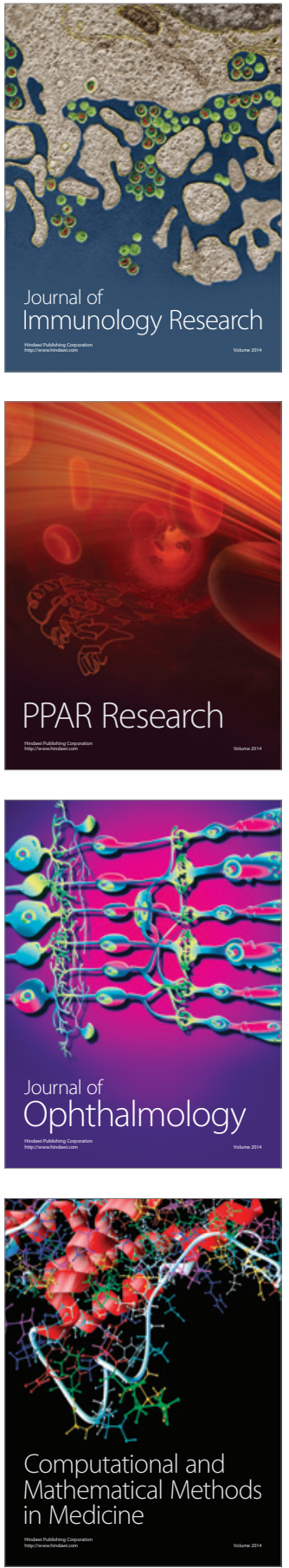

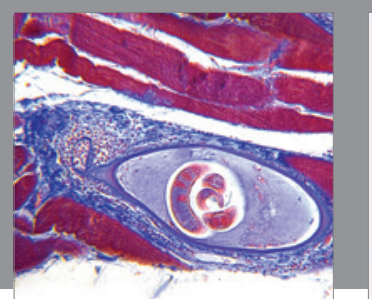

Gastroenterology Research and Practice

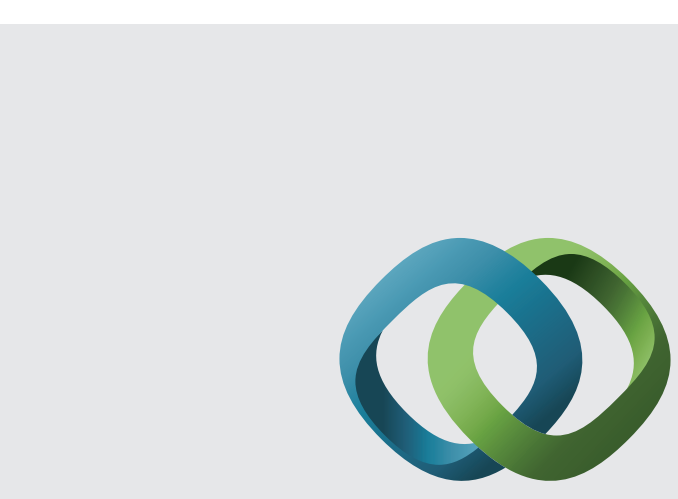

\section{Hindawi}

Submit your manuscripts at

http://www.hindawi.com
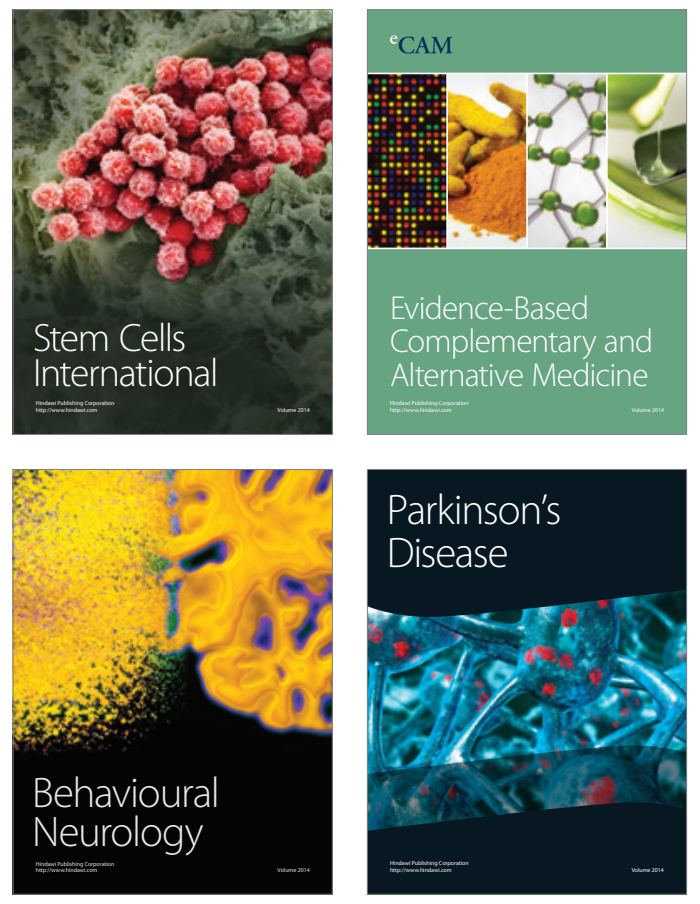
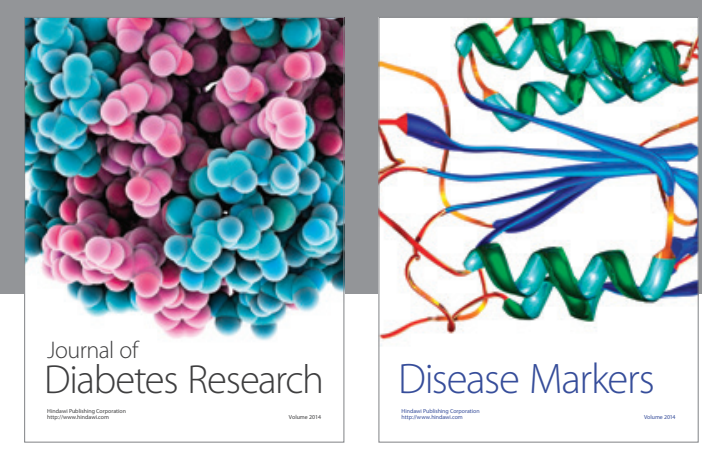

Disease Markers
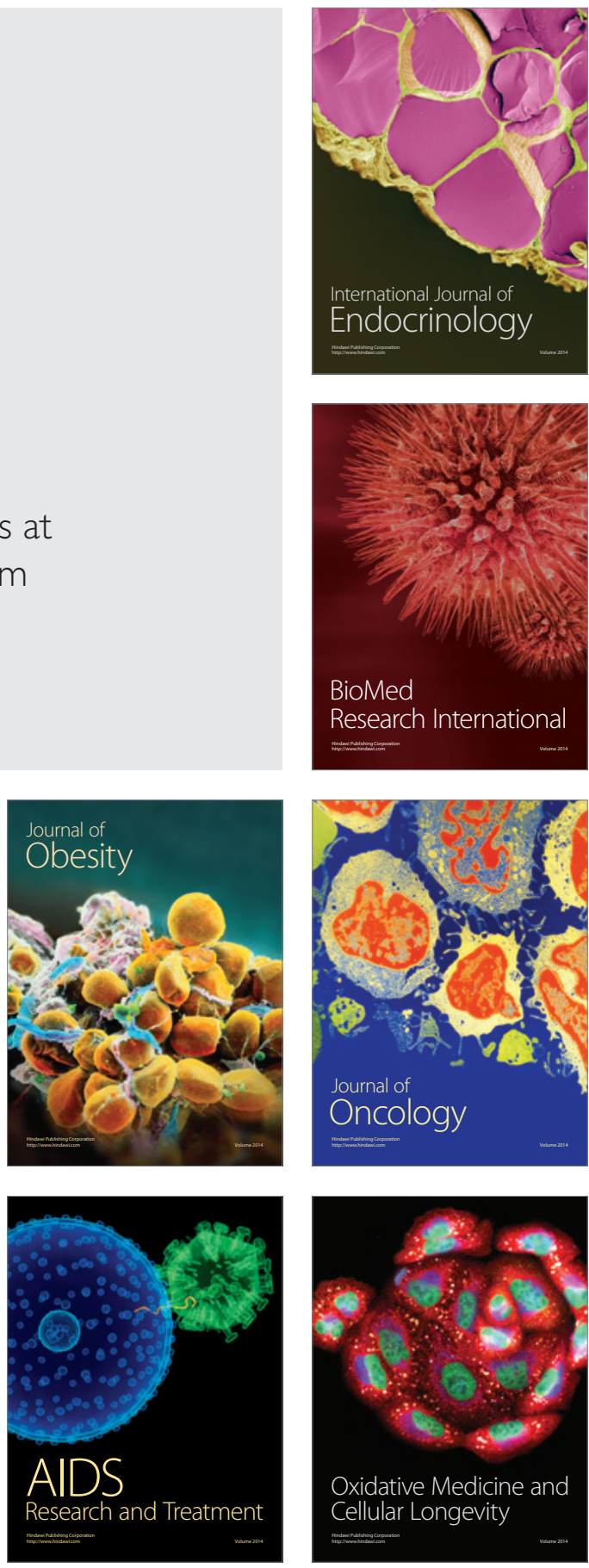